\title{
Embryo-Derived Chemokine CXCL12 Enhances Pregnancy Outcome via Improvement of Endometrial Receptivity
}

Hwa Seon Koo

CHA Bundang Medical Center

Min-Ji Yoon

CHA University

Seon-Hwa Hong

CHA Bundang Medical Center

Jungho Ahn

CHA University

Hwijae Cha

CHA University

Danbi Lee

CHA University

Hwang Kwon

CHA Bundang Medical Center

Dong Hee Choi

CHA Bundang Medical Center

Kyung-Ah Lee

CHA University

Jung-Jae Ko

CHA University

YOUN-JUNG KANG ( $\square$ yjkang@cha.ac.kr)

CHA University

\section{Research}

Keywords: Embryo implantation, Chemokine CXCL12, Endometrial receptivity, Angiogenesis, Infertility

Posted Date: July 28th, 2020

DOI: https://doi.org/10.21203/rs.3.rs-41890/v1 
License: (c) (i) This work is licensed under a Creative Commons Attribution 4.0 International License. Read Full License 


\section{Abstract}

Background: Successful pregnancy inevitably depends on the implantation of a competent embryo into a receptive endometrium. Although a remarkable improvement of assisted reproductive technology (ART) has been achieved over the last few decades, there are still a number of infertile women experiencing frequent ART failure after repeated attempts due to many unsolved problems including repeated failure of implantation. Many substances have been suggested to improve the rates of embryo implantation by enhancing the endometrial receptivity for the patients who are suffering from repeated failure of implantation. However, despite these numerous extensive research work, there are currently no effective evidence-based treatments to prevent or cure this condition. Therefore, here we aim to suggest noninvasive intra-uterine administration of embryo-secreted chemokine CXCL12 as an effective therapeutic intervention to solve this problem.

Results: We demonstrated that chemokine CXCL12 is derived from pre- and peri-implanting embryos and its interaction with endometrial CXCR4 and CXCR7 enhances endometrial receptivity and significantly promoted endothelial vessel formation and sprouting in vitro. Consistently, intra-uterine CXCL12 administration in vivo, which is a completely non-invasive treatment strategy, improved endometrial receptivity showing increased integrin b3 and its ligand osteopontin, and induced endometrial angiogenesis displaying increased numbers of vessel formation near the lining of endometrial epithelial layer with higher CD31 and CD34 expression. Furthermore, intra-uterine CXCL12 application dramatically promoted the rates of embryo implantation with no morphologically retarded embryos.

Conclusions: Our present study provides a novel evidence that improved uterine endometrial receptivity and enhanced angiogenesis induced by embryo-derived chemokine CXCL12 may aid to develop a noninvasive therapeutic strategy for clinical treatment or supplement for the patients with repeated implantation failure with less risk.

\section{Introduction}

Even though a remarkable improvement of assisted reproductive technology (ART) has been achieved for the last several decades, there are still a number of infertile women experiencing frequent ART failure after repeated attempts due to many unsolved problems including repeated failure of implantation. Embryo implantation is a pivotal step in reproduction involving sequential events of complex signaling networks between the embryo and endometrium [1, 2]. Prior to implantation, the endometrium undergoes spatial and temporal dynamic changes, which are driven by ovarian steroid hormones to establish sufficient endometrial receptivity [2,3]. Due to the inaccessible nature and the lack of a standard tool to examine the pre- and peri-implantation phases of pregnancy in human, it has not been possible to fully estimate the proportion of implantation failure [4]. It has been reported that success rates of embryo implantation after fresh cycles of in vitro fertilization-embryo transfer (IVF-ET) process only lie at around $25-30 \%[5,6]$. This implies that despite the extensive improvement of assisted reproductive technology, there are still meaningful proportion of refractory infertilities suffering from repeated implantation failure 
(RIF) or repeated pregnancy failure indicating the embryo implantation might be the rate-determining factor in infertility [7-9]. RIF is usually defined as "failure of more than three cycles of IVF-ET in which reasonably good embryos were transferred", which occurs in 15-20\% of infertile women [10]. Among the factors that attributes to RIF; unreceptive endometrium, poor embryos, and unsynchronized maternal-fetal crosstalk; defects in endometrial receptivity accounts for the half of implantation failures in women suffering from RIF after embryo transfer [11, 12]. Although there have been extensive studies to identify the multi-omic signatures of endometrium of RIF patients compared to normal women [13-15], pathophysiological features of the endometrium with poor receptivity have not been fully elucidated yet.

Angiogenesis is a process of new vessel formation from the existing vascular structure by elongation and intussusception [16]. In particular, endometrial angiogenesis plays a critical role in various female reproductive processes including folliculogenesis, cyclic endometrial regeneration, embryo implantation and placentation [17-19]. It has been reported that endometrial vasculature affects endometrial receptivity and especially determines the endometrial response to the blastocyst at the early stage of embryo implantation $[20,21]$. The endometrium becomes thicker with mature vascular network and increased blood flow, which reflect sufficient endometrial receptivity during the implantation [21]. Various substances including granulocyte colony-stimulating factor (G-CSF), mesenchymal stem cells (MSC), and platelet-rich plasma (PRP) have been suggested to enhance endometrial angiogenesis and receptivity for patients who are suffering from implantation failure with poor endometrial receptivity [22-24]. However, the efficacy of those substances still has not been fully evidenced yet [25-27].

The chemokine (C-X-C motif) CXCL12, stromal cell derived factor 1a (SDF1a), and its ligands CXCR4 and CXCR7 are widely distributed in endometrial and placental tissues playing vital roles in embryonic development, implantation, placentation, and immune responses at the maternal-fetal interface $[9,28$, 29]. CXCL12 has been reported to be expressed in human mature oocytes and fertilized egg [30]. Additionally, it promotes the migration and invasion of human first-trimester trophoblast cells inducing placental angiogenesis to form maternal decidual vasculature via its interaction with endometrial CXCR4 and CXCR7 [31]. Even though several recent studies have suggested the critical roles of CXCL12 in female reproductive processes, there are few reports on the assessment of potential capacity of this chemokine CXCL12 as a therapeutic intervention to directly improve the implantation and pregnancy rates, which might be applicable for the patients suffering from repeated failure of implantation. In this study, we validated CXCL12 as a secreted factor from the embryo and explored the impact of intrauterine CXCL12 treatment on the endometrial receptivity and the induction of endometrial angiogenesis. In addition, we further examined the effect of CXCL12 on improvement of the rates of embryo implantation and pregnancy.

\section{Materials And Methods}

\section{Animals}


Six-week-old C57BL/6 female and seven-week-old male mice (Orientbio, Gapyeong, Gyeonggi, South Korea) were used for the analyses and evaluation of impact of CXCL12. All experiments were carried out in accordance with the policies of the CHA University Institutional Animal Care and Use Committee (IACUC, approval number 190126). All mice were housed under standard environmental conditions of $12 \mathrm{~h}$ light: $12 \mathrm{~h}$ dark at a controlled room temperature $\left(20-22^{\circ} \mathrm{C}\right.$ and $40-60 \%$ humidity) and fed ad libitum.

\section{Cell culture and CXCL12 treatment}

Human endometrial epithelial Ishikawa cells (ATCC) were maintained in DMEM/F12 media (Gibco, Grand Island, NY, USA) supplemented with 10\% fetal bovine serum (Gibco, Grand Island, NY, USA) and 1\% penicillin-streptomycin (Gibco, Grand Island, NY, USA) as previously described [32]. For tube formation and sprouting assays, Human Umbilical Vein Cells (HUVEC, ATCC) and Human Endometrial Microvascular Endothelial Cells (HEMEC, PromoCell) were maintained in EGM ${ }^{\mathrm{TM}}$-2 endometrial cell growth medium 2 (Lonza) and Endothelial Cell Growth Medium MV (PromoCell), respectively. Human recombinant CXCL12 (100 ng/ml, Peprotech, USA) was used for further analyses.

\section{Mouse embryo collection and co-culture}

For the embryo collection, female mice were super-ovulated with intraperitoneal injection of pregnant mare serum gonadotropin (PMSG-10 IU, Daesung Microbiological, Korea) and ovulation was synchronized by human chorionic gonadotropin (hCG-5 IU, Sigma, USA) injection. Females were placed singly with males of the same strain overnight. The morning of the presence of a vaginal plug was designated day 1 of pregnancy. Pregnant mice were killed on day 1 . One-cell embryos were obtained from the oviduct using a $30 \mathrm{G}$ dissecting needle of $1 \mathrm{ml}$ syringe to tear open the ampulla of the oviduct and release. Cumulus cell around of the one-cell embryo were washed with $0.1 \%$ hyaluronidase drop at $37^{\circ} \mathrm{C}$ for 5-10 min and dissociated by gentle pipetting to glass pipettes. Collected embryos were washed with M2 media (Sigma, USA) supplemented with $4 \mathrm{mg} / \mathrm{ml} \mathrm{BSA}$ and cultured in a $20 \mu \mathrm{l}$ drop of KSOM (Millipore, USA) covered with mineral oil at $5 \% \mathrm{CO}_{2}, 37^{\circ} \mathrm{C}$ until the blastocyst stage. Only expanded blastocysts with clearly observable inner cell mass and trophectoderm on day 5 were included in the study. Day 5 blastocysts were transferred to confluent Ishikawa cell monolayer grown on the Matrigelcoated cover glass. Co-cultures were maintained undisturbed at $37{ }^{\circ} \mathrm{C}$ in a $5 \% \mathrm{CO}_{2}$ for $48 \mathrm{~h}$, and finally fixed in 4\% paraformaldehyde in PBS for 15 min at room temperature as previously described [33].

\section{Sandwich-Type Enzyme-Linked Immunosorbent Assay for CXCL12 detection}

Embryo-derived chemokine CXCL12 protein levels in the embryo culture media were determined by sandwich-type enzyme-linked immunosorbent assays (ELISA) according to the manufacturer's instructions (R\&D, USA). Two hundred microliters of embryo culture media were collected from 15 mouse embryos and pooled. Samples were assayed in triplicate. CXCL12 levels were assayed using a validated 
commercial ELISA (DY008: DuoSet ELISA Ancillary Reagent Kit 2, R\&D, USA). The absorbance was read at $450 \mathrm{~nm}$ in a 96-well microtiter plate reader.

\section{Assessment of vessel formation}

Assessment of the rates of endothelial tube formation with or without CXCL12 $(0,100$ and $200 \mathrm{mg} / \mathrm{ml})$ administration was performed. HUVECs or HEMECs were seeded $\left(2 \times 10^{4}\right.$ cells/well) onto growth factor reduced Matrigel (\#354230, Corning Inc., Corning, NY, USA) pre-coated wells in $100 \mu$ l of appropriate cell growth media. Following incubation at $37^{\circ} \mathrm{C}$ overnight, each well was analyzed directly under a microscope. The images (10X magnification) were subsequently analyzed using Image J.

\section{Assessment of endothelial sprouting}

As previously reported [34], a microengineered vascular system was designed to investigate endothelial cell responses to CXCL12 in a 3-dimensional vascularized network. To fabricate the devices, SU-8 (MicroChem) was spun onto $100 \mathrm{~mm}$ silicon wafers to a height of $100 \mu \mathrm{m}$ before undergoing photolithography. The wafers were developed and dried before casting. Polydimethylsiloxane (PDMS, Sylgard 184, Dow Corning) was molded to the patterned silicon wafer using a 10:1 mass ratio of elastomer to curing agent before curing at $80^{\circ} \mathrm{C}$. Molded devices were then bonded to glass coverslip using oxygen plasma for $1 \mathrm{~min}$. The microfluidic devices were incubated in an $80^{\circ} \mathrm{C}$ dry oven for at least $48 \mathrm{~h}$ to restore hydrophobicity of PDMS. The devices were sterilized by UV irradiation before use. CRL4003 $\left(8 \times 10^{6} / \mathrm{ml}\right)$ cell were mixed with fibrinogen solution $(2.5 \mathrm{mg} / \mathrm{ml}$ fibrinogen with $0.15 \mathrm{U} / \mathrm{ml}$ aprotinin). Thrombin $(0.5 \mathrm{U} / \mathrm{ml})$ was added to cell mixture and immediately loaded into the channel for stromal cell. Fibrinogen solution $(2.5 \mathrm{mg} / \mathrm{ml}$ fibrinogen with $0.15 \mathrm{U} / \mathrm{ml}$ aprotinin) was mixed with thrombin $(0.5 \mathrm{U} / \mathrm{ml})$ was applied to the vessel channel. After allowing the gels to polymerize for $3 \mathrm{~min}$ at room temperature, the inlet reservoirs of the cell culture medium channels were filled with EGM-2 medium, and then aspirated to fill the hydrophobic channels. Following loading all four reservoirs, HUVECs $(5 \times$ $10^{6} / \mathrm{ml}$ ) were introduced into the media channel. The device was then tilted $90{ }^{\circ} \mathrm{C}$ in an incubator for $40 \mathrm{~min}$ to attach the cell mixture to the gel-media interface. After allowing HUVECs to adhere on the fibrin gel surface, the microfluidic devices were incubated for 7 days until fully lumenized microvessels had formed. In order not to disturbed by the interstitial flow, all microfluidic experiments were conducted under static condition.

\section{Intra-uterine infusion of CXCL12 and fertility assessment}

The female mice were anesthetized via intraperitoneal injection of tribromoethanol (avertin). A vertical incision was made to expose the uterus in the abdominal wall. CXCL12 was prepared in $30 \mu$ of saline and infused using 31-gauge insulin syringe into one side of mouse uterine cavities and saline was infused into the other side of horns for the control. After 8 days of CXCL12-infusion, female mice were weakly stimulated for the ovulation with $2.5 \mathrm{IU}$ of PMSG and $1.25 \mathrm{IU}$ of hCG injection. The presence of a vaginal plug the following morning (day 1 of pregnancy) was used as an indicator of successful mating. For the fertility assessment depending on the intra-uterine CXCL12 treatment, both sides of uterine horns 
were obtained 16 days after mating for the analyses of the rates for embryo implantation and pregnancy maintenance.

\section{Library preparation and sequencing for RNA-seq analysis}

For control and test RNAs, the construction of library was performed using QuantSeq 3' mRNA-Seq Library Prep Kit (Lexogen, Inc., Austria) according to the manufacturer's instructions. In brief, each $500 \mathrm{ng}$ total RNA was prepared and an oligo-dT primer containing an Illumina-compatible sequence at its $5^{\prime}$ end was hybridized to the RNA and reverse transcription was performed. After degradation of the RNA template, second strand synthesis was initiated by a random primer containing an Illumina-compatible linker sequence at its 5 ' end. The double-stranded library was purified by using magnetic beads to remove all reaction components. The library was amplified to add the complete adapter sequences required for cluster generation. The finished library is purified from PCR components. High-throughput sequencing was performed as single-end 75 sequencing using NextSeq 500 (Illumina, Inc., USA). The raw and normalized data have been deposited in the Gene Expression Omnibus (GEO) data base (accession number: GSE154039).

\section{Data analysis}

QuantSeq 3' mRNA-Seq reads were aligned using Bowtie2 (Langmead and Salzberg, 2012). Bowtie2 indices were either generated from genome assembly sequence or the representative transcript sequences for aligning to the genome and transcriptome. The alignment file was used for assembling transcripts, estimating their abundances and detecting differential expression of genes. Differentially expressed gene were determined based on counts from unique and multiple alignments using coverage in Bedtools (Quinlan AR, 2010). The RC (Read Count) data were processed based on quantile normalization method using EdgeR within $\mathrm{R}$ ( $\mathrm{R}$ development Core Team, 2016) using Bioconductor (Gentleman et al.,2004). Gene classification for Gene Ontology (G0) and pathway analysis was performed by DAVID (http://david.abcc.ncifcrf.gov/) and Medline databases (http://www.ncbi.nlm.nih.gov/). The significance cutoffs were set for fold-change $(\geq 2)$, P-value $(<0.05)$ and FDR (0.05).

\section{Immunohistochemistry}

Histology and immunohistochemistry were performed as described [35] by using antibodies to Integrin $\beta 3$ (Cell Signaling; \#13166; 1:100), and OPN (Enzo; ADI-905-629; 1:100) and detected with HRP-conjugated anti-mouse or rabbit secondary antibodies, and counterstained with DAPI (Sigma).

\section{Immunofluorescence and microscopy}

Immunofluorescence staining was performed as previous described [35]. Localization studies were performed using antibody to CXCR4 (Invitrogen; PA3-305, 1:100), CXCR7 (Novus; NBP2-58162, 1:100), integrin avß3 (MILLIPORE; MAB1976, 1:100), HIF1a (Cell signaling technology; \#3434, 1:50), CD31 (abcam; ab28364, 1:100), and CD34 (abcam; ab8563, 1:100), and further incubated with anti-rabbit IgG fluorescence (Invitrogen) or anti-mouse IgG fluorescence (Invitrogen). Cover glasses were mounted in 
Vectashield mountant with DAPI (Vector Laboratories) as nuclear stain. Images were captured using oil immersion 63x objectives Zeiss 510 microscopy (Carl Zeiss Microlmaging, Röttingen, Germany) and processed using Zen software (ZEISS), and particularly images for 3-dimensional endothelial sprouting stained with Alexa Fluor ${ }^{\circledR} 488$ conjugated monoclonal antibody against CD31 (1:200) (Invitrogen) and Hoechst 33342 (1:1000) (Thermo Fisher scientific) were captured using a confocal microscope (Olympus FV1000, Zeiss LSM 880). Z-projection of the 3D stacks of microvascular network were obtained with ZEISS ZEN lite, and further analyzed with Image $(\mathrm{NIH})$ to obtain binary images and calculate the proportion of the fluorescent pixels within the ROI of each image, deriving the angiogenic sprout area coverage in the vessel channel.

\section{Quantitative RT-PCR-based analysis of mRNA expression}

SYBR Green (Roche, Basel, Switzerland) assay were used to quantitate endometrial receptivity- or angiogenesis-related genes in CXCL12-treated and control samples. Total RNA extracted using TRIzol reagent (Ambion, Life Technologies Corporation, CA, USA) at 1 ug was converted to cDNA using M-MLV reverse transcriptase (Promega, Madison, WI, USA), dNTP (Invitrogen, Carlsbad, CA, USA) and oligo dT primer (Labopass, Seoul, Korea). With 1/10 volume of CDNA, gene expression was quantitatively analyzed. Amplifications were run in a CFX Connect ${ }^{\text {TM }}$ Real-Time PCR Detection System (BioRad, Hercules, CA, USA). A DNA melting-curve was used to confirm the presence of a single PCR product in each assay. Real-time PCR results for endometrial receptivity- or angiogenesis-related genes were normalized to $\beta$ actin mRNA expression and analyzed using the ordinary one-way ANOVA analysis with Dunnett's multiple comparison tests. Primer sequence pairs used for these analyses are shown in Supplementary Table 1.

\section{Statistical analysis}

Comparison groups were analyzed with unpaired Student t-test for parametric distributions. For multiple comparisons, the ordinary one-way ANOVA analysis with Dunnett's multiple comparison test. For all cases, a $\mathrm{P}$-value that was $<0.05$ was considered statistically significant $\left(\mathrm{P}<0.05\left({ }^{\star}\right), \mathrm{P}<0.01(\star \star), P<\right.$ $0.001(\star \star \star)$ and $P<0.0001(\star \star \star \star))$.

\section{Results}

\section{Embryo-derived CXCL12 induced endometrial CXCR4/CXCR7}

To validate the secretion of CXCL12 from the pre- or peri-implanting embryos, micro-droplets of day 3-4 mouse embryo culture media and control empty media maintained under identical culture conditions were collected and pooled up to $200 \mu \mathrm{l}$ of volume each and CXCL12 concentration in the embryo culture media was measured using an ELISA kit (R\&D, USA). Detection of CXCL12 protein in mouse embryo culture media was confirmed by the comparison of levels of CXCL12 detected in empty media (Fig. 1a). To further investigate the impact of embryo-secreted CXCL12 on the endometrial epithelium on which the implanting embryo is firstly placed inside the maternal uterus, day 5 mouse embryos were transferred to 
confluent Ishikawa cells and incubated for $48 \mathrm{~h}$. Embryos were attached stably to the endometrial epithelial layer of Ishikawa cells. Each image including an attached embryo (red spot, white arrow) located on Matrigel-coated coverslip was shown (Fig. 1b). A well-known ligand for CXCL12, CXCR4 was locally elevated at the site of attached mouse embryo, while being unaffected further away from the attachment site (Fig. 1C). The intensity of CXCR4 expression in each image was further quantified by surface profiling (Fig. 1C). No changes in CXCR4 expression was detected in Ishikawa cells in the absence of co-cultured embryo (Fig. S1a-S1b). CXCR7, a ligand of CXCL12, was also shown the increased expression near the embryo attachment site (red spot, white arrow) compared to the expression level away from the attached embryo (Fig. S1c-S1d). Next, CXCL12 was globally applied to endometrial epithelial Ishikawa cells in vitro and examined the changes in levels of CXCR4 and CXCR7, well-known ligands for CXCL12. Immunofluorescence (IF) staining analyses revealed that the expression levels of CXCR4 and CXCR7 were highly increased in Ishikawa cells with CXCL12 treatment compared to controls (Fig. 1d). Additionally, the expression levels of integrin av $\beta 3$ and HIF1a, surrogate markers of endometrial receptivity, were dramatically increased in Ishikawa cells upon CXCL12 treatment (Fig. 1e), which are consistent with previously reported findings $[36,37]$. In particular, both expressions of integrin av $\beta 3$ and HIF1 a were elevated in the cytoplasmic compartment. These data might suggest that embryo-secreted chemokine CXCL12 increases the local crosstalk between the embryo and endometrium by activating its ligands, CXCR4/CXCR7 in the endometrium, and enhances endometrial receptivity.

\section{Effect of CXCL12 on endothelial angiogenesis}

Angiogenesis involves the proliferation and migration of endothelial cells, which are then reorganized into tubular formations to form vessel networks $[38,39]$. To examine the effect of CXCL12 on the ability of tube formation of human endothelial cells, we plated HUVECs (human umbilical vein cells) or HEMEC (human endometrial microvascular endothelial cells) onto Matrigel-coated plate and human recombinant CXCL12 protein $(100 \mathrm{ng} / \mathrm{ml}$ or $200 \mathrm{ng} / \mathrm{ml})$ was applied. The capacity of tube formation was quantified by measuring the total number of tube loops and branching points. These analyses revealed that CXCL12 significantly enhances the rates of tube formation of HUVECs (Fig. 2a-2b) or HEMECs (Fig. 2c-2d) compared to saline-treated controls. Interestingly, no significant difference was observed between the total number of tube formation at $200 \mathrm{ng} / \mathrm{ml}$ of CXCL12-treated condition and that of $100 \mathrm{ng} / \mathrm{ml}$ of CXCL12 indicating that higher concentration of CXCL12 is not essentially required for the induction of appropriate levels of endometrial angiogenesis. Furthermore, we implemented a micro-engineered 3dimensional angiogenesis system to explore the effect of CXCL12 on the ability of endothelial sprouting. The device consists of 5 primary channels; 2 fluidic microchannels separate 3 hydrogel-laden microchannels from each other to facilitate the supply of fresh media through the device (Fig. 2e). This multi-channel co-culture system facilitates the paracrine interaction between HUVECs and endometrial stromal layer, mediating the process of angiogenic morphogenesis. The micro-engineered angiogenesis multi-channel co-culture system was exposed to CXCL12 $(100 \mathrm{ng} / \mathrm{ml}$ or $200 \mathrm{ng} / \mathrm{ml})$. These analyses revealed that the administration of CXCL12 elevated the angiogenic effect of HUVECs displaying 
increased numbers and surface area of endothelial sprouting (Fig. 2e-2f), which is consistent with data from tube formation assay using HUVECs or HEMECs.

\section{Identification of alterations in gene expression induced by intrauterine CXCL12 infusion in mice}

CXCL12-CXCR4 axis is involved in several critical reproductive biological processes including uterine killer cell recruitment, placentation, embryo implantation and embryogenesis [40]. To induce the conversion of the local effect of embryo-secreted CXCL12 globally to the entire endometrium, recombinant human CXCL12 protein was infused into one side of mouse uterine horns and saline was infused into the other side of horns for the comparison (Fig. 3a). One hundred nanograms of recombinant human CXCL12, which was determined based on the analyses of CXCL12-induced endothelial tube formation (Fig. 2), was prepared in $30 \mu \mathrm{l}$ of saline-based solution. Leakage of intra-uterine administered CXCL12 from one side of horn to the other was prevented as possible by adjusting the appropriate volume of solution. Mice were monitored by examining dry tissue placed under the body during anaesthesia recovery [41]. Little leakage was observed. Mouse uterine tissues were obtained 3 and 8 days after CXCL12 administration (Fig. 3a). Differential gene expression data were generated from CXCL12-treated (Day 3 and Day 8) endometrial tissues compared to control (saline-treated). Unsupervised hierarchical clustering analyses using a fold change cutoff of 2 and a P-value cutoff of 0.05 identified a total of 1724 (985 genes were up-regulated and 739 genes were down-regulated) differentially expressed genes in CXCL12-Day 8 groups (Fig. 3b). To classify 1724 differentially expressed genes by their functional annotations, gene ontology (GO) and pathway analyses were performed by using the Database for Annotation, Visualization and Integrated Discovery (DAVID) online tools [42]. Enriched GO terms in each category and pathway including associated-gene counts, P-value, and fold enrichment (FE) calculated by Fisher's exact test and multiple comparisons test, respectively $(P<0.05$ and $F E>1.5)$, are visualized in Fig. 3c-3e. A total of 1724 differentially expressed genes were classified according to GO terms, including biological process, BP; cellular component, CC; molecular function, MF (Fig. 3c-3e, Table 1). Whole gene ontology and pathway analyses demonstrate that CXCL12-administered uterine tissues induce the enrichment of specific BP categories, including response to estradiol $(P=0.00482)$, positive regulation of vasodilation $(P=0.00287)$, cell adhesion $(P=0.00203)$, and cell surface receptor signaling pathway $(P=0.000637)$. This might suggest that intra-uterine treatment of CXCL12 induces biological processes particularly related to endometrial angiogenesis and the activation of cell surface receptor signaling mediating cell-cell adhesion, which might be the initial stage of embryo-endometrial crosstalk during the embryo implantation [1]. Moreover, enriched terms of the CC category include integral components of external side of plasma membrane $(P=0.00228)$, proteinaceous extracellular matrix $\left(P=4.47 x \mathrm{E}^{-05}\right)$, extracellular region $\left(P=9.5 x \mathrm{E}^{-25}\right)$, extracellular space $\left(P=4.66 \mathrm{xE}^{-09}\right)$, and basement membrane $(P=0.04551)$. Chemokine activity $(P=0.0371)$, cytokine activity $(P=0.0265)$, signal transducer activity $(P=0.0222)$, protein homodimerization activity $(P=0.0195)$, and vitamin $\mathrm{D}$ binding $(P=0.0097)$ were composed of enriched MF terms. These analyses implicate that intrauterine administration of chemokine CXCL12 might induce the intra- and inter-cellular signaling via binding to chemokine receptor CXCR4 or CXCR7 
and activating cell surface receptors, such as G-protein alpha subunit, vitamin D, heparin binding, and insulin-activated receptor as second messengers to possibly result in promoting angiogenesis and mediating embryo implantation $[43,44]$, which is supported by enrichment of signal transducer activity classified in BP and MF categories. Furthermore, in-depth clustering analyses of enriched GO categories of CXCL12-treated uterus compared to saline-treated tissue were performed by ClueGO. These analyses revealed that CXCL12-induced enrichment particularly includes embryo implantation, sprouting angiogenesis, $\mathrm{GnRH}$ secretion, regulation of vasculature development, regulation of epidermal growth factor receptor signaling pathway, regulation of collagen metabolic process, and regulation of muscle contraction (Fig. 3f). 
Table 1

Whole Gene ontology (GO) and pathway analysis of differentially expressed genes of CXCL12-day8 samples compared to control using DAVID tool. The cutoff for significance was set by P-value $<0.05$ and Fold Enrichment (FE) $>1.5$. biological process (BP), cellular component (CC), and molecular function (MF) annotations.

\begin{tabular}{|c|c|c|c|c|}
\hline Category & Term & Count & P-value & $\begin{array}{l}\text { Fold } \\
\text { Enrichment }\end{array}$ \\
\hline $\begin{array}{l}\text { Biological } \\
\text { process (BP) }\end{array}$ & GO:0032355 response to estradiol & 9 & $4.82 \mathrm{E}^{-03}$ & 3.421 \\
\hline $\begin{array}{l}\text { Biological } \\
\text { process (BP) }\end{array}$ & $\begin{array}{l}\text { G0:0045909 } \sim \text { positive regulation of } \\
\text { vasodilation }\end{array}$ & 6 & 0.00287 & 6.062 \\
\hline $\begin{array}{l}\text { Biological } \\
\text { process (BP) }\end{array}$ & GO:0007155 cell adhesion & 25 & 0.00203 & 1.979 \\
\hline $\begin{array}{l}\text { Biological } \\
\text { process (BP) }\end{array}$ & $\begin{array}{l}\text { GO:0050728 negative regulation of } \\
\text { inflammatory response }\end{array}$ & 9 & 0.00191 & 3.971 \\
\hline $\begin{array}{l}\text { Biological } \\
\text { process (BP) }\end{array}$ & $\begin{array}{l}\text { GO:0010628 positive regulation of gene } \\
\text { expression }\end{array}$ & 23 & $\begin{array}{l}8.10 \mathrm{E}^{-} \\
04\end{array}$ & 2.213 \\
\hline $\begin{array}{l}\text { Biological } \\
\text { process (BP) }\end{array}$ & GO:0006955 immune response & 18 & $\begin{array}{l}8.05 \mathrm{E}^{-} \\
04\end{array}$ & 2.541 \\
\hline $\begin{array}{l}\text { Biological } \\
\text { process (BP) }\end{array}$ & $\begin{array}{l}\text { GO:0007166 cell surface receptor signaling } \\
\text { pathway }\end{array}$ & 16 & $\begin{array}{l}6.37 \mathrm{E}^{-} \\
04\end{array}$ & 2.805 \\
\hline $\begin{array}{l}\text { Biological } \\
\text { process (BP) }\end{array}$ & $\begin{array}{l}\text { Go:0010907 positive regulation of glucose } \\
\text { metabolic process }\end{array}$ & 6 & $\begin{array}{l}1.67 \mathrm{E}^{-} \\
04\end{array}$ & 10.97 \\
\hline $\begin{array}{l}\text { Biological } \\
\text { process (BP) }\end{array}$ & GO:0071396 cellular response to lipid & 6 & $\begin{array}{l}2.81 \mathrm{E}^{-} \\
05\end{array}$ & 15.36 \\
\hline $\begin{array}{l}\text { Cellular } \\
\text { component (CC) }\end{array}$ & GO:0005576 extracellular region & 125 & $9.5 \mathrm{E}^{-25}$ & 2.665 \\
\hline $\begin{array}{l}\text { Cellular } \\
\text { component (CC) }\end{array}$ & GO:0005615 extracellular space & 80 & $\begin{array}{l}4.66 \mathrm{E}^{-} \\
09\end{array}$ & 1.988 \\
\hline $\begin{array}{l}\text { Cellular } \\
\text { component (CC) }\end{array}$ & $\begin{array}{l}\text { GO:0005578 proteinaceous extracellular } \\
\text { matrix }\end{array}$ & 23 & $\begin{array}{l}4.47 \mathrm{E}^{-} \\
05\end{array}$ & 2.721 \\
\hline $\begin{array}{l}\text { Cellular } \\
\text { component (CC) }\end{array}$ & $\begin{array}{l}\text { GO:0009897 external side of plasma } \\
\text { membrane }\end{array}$ & 19 & 0.00228 & 2.24 \\
\hline $\begin{array}{l}\text { Cellular } \\
\text { component (CC) }\end{array}$ & G0:0005604 basement membrane & 7 & 0.04551 & 2.24 \\
\hline $\begin{array}{l}\text { Molecular } \\
\text { function (MF) }\end{array}$ & GO:0008009 chemokine activity & 5 & 0.0371 & 3.951 \\
\hline
\end{tabular}




\begin{tabular}{|c|c|c|c|c|}
\hline Category & Term & Count & P-value & $\begin{array}{l}\text { Fold } \\
\text { Enrichment }\end{array}$ \\
\hline $\begin{array}{l}\text { Molecular } \\
\text { function (MF) }\end{array}$ & GO:0005125 cytokine activity & 12 & 0.0265 & 2.127 \\
\hline $\begin{array}{l}\text { Molecular } \\
\text { function (MF) }\end{array}$ & GO:0008237 metallopeptidase activity & 10 & 0.0259 & 2.37 \\
\hline $\begin{array}{l}\text { Molecular } \\
\text { function (MF) }\end{array}$ & GO:0005102 receptor binding & 19 & 0.0251 & 1.749 \\
\hline $\begin{array}{l}\text { Molecular } \\
\text { function (MF) }\end{array}$ & GO:0004871 signal transducer activity & 27 & 0.0222 & 1.58 \\
\hline $\begin{array}{l}\text { Molecular } \\
\text { function (MF) }\end{array}$ & $\begin{array}{l}\text { GO:0042803 protein homodimerization } \\
\text { activity }\end{array}$ & 32 & 0.0195 & 1.521 \\
\hline $\begin{array}{l}\text { Molecular } \\
\text { function (MF) }\end{array}$ & GO:0042379 chemokine receptor binding & 4 & 0.011 & 8.428 \\
\hline $\begin{array}{l}\text { Molecular } \\
\text { function (MF) }\end{array}$ & $\begin{array}{l}\text { GO:0001965 G-protein alpha-subunit } \\
\text { binding }\end{array}$ & 5 & 0.0106 & 5.746 \\
\hline $\begin{array}{l}\text { Molecular } \\
\text { function (MF) }\end{array}$ & GO:0005499 vitamin D binding & 3 & 0.0097 & 18.96 \\
\hline $\begin{array}{l}\text { Molecular } \\
\text { function (MF) }\end{array}$ & GO:0008201 heparin binding & 11 & 0.0067 & 2.763 \\
\hline $\begin{array}{l}\text { Molecular } \\
\text { function (MF) }\end{array}$ & $\begin{array}{l}\text { GO:0048020 CCR chemokine receptor } \\
\text { binding }\end{array}$ & 5 & 0.0059 & 6.773 \\
\hline $\begin{array}{l}\text { Molecular } \\
\text { function (MF) }\end{array}$ & G0:0030246 carbohydrate binding & 15 & 0.0031 & 2.484 \\
\hline $\begin{array}{l}\text { Molecular } \\
\text { function (MF) }\end{array}$ & $\begin{array}{l}\text { GO:0005009 insulin-activated receptor } \\
\text { activity }\end{array}$ & 5 & $2.8 \mathrm{E}^{-04}$ & 14.59 \\
\hline
\end{tabular}

\section{Intra-uterine CXCL12 treatment increases uterine receptivity}

The hematoxylin and eosinophil (H\&E) staining of paraffin-embedded uterus sections revealed that no significant histological alterations were observed with CXCL12 infusion (Fig. 4a). Interestingly, increased thickness of uterine wall and decreased surface area of uterine cavity were observed in CXCL12-treated uterus exhibiting higher numbers of uterine glands compared to the other side of control tissues, which are the important features that can be observed in the fertile endometrium during the time of window of implantation compared to infertile women [45]. This might suggest that intra-uterine CXCL12 administration provides a better uterine environment for the embryo implantation and pregnancy. In order to examine the direct impacts of intra-uterine CXCL12 infusion on the alterations in global gene expression related to uterine receptivity, total RNA was extracted from the whole uterine tissues; one from CXCL12-treated and the other from saline-treated side. This comparison revealed that uterine receptivityrelated markers, including integrin $\beta 3$, LIF, and glycodelin, [46] showed higher expression levels in 
CXCL12-treated uterine tissue compared to saline-treated one (Fig. 4b-4d). Our further interrogation with immunohistochemical staining of integrin $\beta 3$ and one of its ligand osteopontin (OPN) using paraffinembedded CXCL12- or saline-treated uterine tissue sections demonstrated dramatically elevated levels of both integrin $\beta 3$ and OPN in CXCL12-treated uterus compared to control (Fig. 4e), suggesting administered CXCL12 directly or indirectly induces integrin $\beta 3-O P N$, adhesion molecules on the surface of endometrial epithelium in mice, which is consistent with the findings from RNA-seq analyses (Fig. 3c; BP and MF). Thus, this implicates that intra-uterine administration of CXCL12 might be an effective therapeutic strategy to improve uterine receptivity.

\section{Intra-uterine CXCL12 treatment promotes uterine angiogenesis}

During the mid-secretory phase, the endometrium becomes mature exhibiting very coiled uterine glands with wide lumen. Increased secretion of progesterone from the corpus luteum enhances uterine thickness and blood flow to spiral arteries, which corresponds with an increased endometrial receptivity during the window of implantation [47-49]. This led us to ask whether intra-uterine infusion of CXCL12 induces endometrial angiogenesis besides the elevation of uterine receptivity by examining the expression pattern of widely-used angiogenesis markers. CD31, also known as platelet and endothelial cell adhesion molecule 1 (PECAM1), is a surrogate marker for blood vessel formation. It has been reported to show significantly increased CD31 expression in the mid-secretory phase of uterus in normal women compared to patients with repeated implantation failure [50,51]. Moreover, CD34 is a transmembrane phosphoglycoprotein and well-studied marker for hematopoietic stem and progenitor cells. Recently, it has been suggested that CD34 is expressed by vascular endothelial progenitors and endometrial stromal stem cells particularly displaying neovascular formation [26, 52]. Immunofluorescence staining of CD31 (Fig. 5a) and CD34 (Fig. 5b) exhibits higher expression levels in CXCL12-treated uterus compared to control revealing CXCL12 treatment enhances new capillary formation from the pre-existing blood vessels in the endometrium. These results were validated with QRT-PCR analyses using samples obtained from the whole mouse uteruses in the presence or absence of CXCL12 intra-uterine administration. Besides of examination for CD31 and CD34, alterations in the expression levels of other well-studied angiogenesis markers including Vegfa, Vegfr1, Tie1, Tie2, Ang1, and Ang2, depending on the CXCL12 treatment were investigated (Fig. 5c-5j). These revealed that CXCL12 treatment significantly induces the levels of angiogenesis-related marker molecules, except for Vegfa and Ang2, in the mouse endometrium, strongly suggesting CXCL12 as an effective intervention to promote the angiogenic effect in the endometrium.

\section{Non-invasive intra-uterine CXCL12 treatment improved pregnancy rates}

We next asked whether CXCL12-induced enhancement of endometrial receptivity and angiogenesis subsequently affects the pregnancy rates. CXCL12 was applied to the mouse uterus in a same manner as shown in Fig. 3a. For the fertility assessment in the presence or absence of CXCL12 treatment, after 8 
days of intra-uterine infusion of CXCL12- or saline, female mice were weakly stimulated for the ovulation with PMSG (2.5 IU) and hCG (1.25 IU) injection. This assists to exclude the issues with the estrous cycle for the fertility assessment. Sixteen days after mating, both sides of uterine horns were harvested to examine the rates of embryo implantation and maintenance of pregnancy (Fig. 6a). Interestingly, the total number of implantation sites in CXCL12-treated uterine horn was significantly higher than saline-treated side $(P=0.0109)$ (Fig. 6b-6c). Of note, no retarded embryos were detected in both groups, however, the weight of day 16 embryos from CXCL12-treated uterus showed slightly higher (1.3-fold: $0.065 \mathrm{~g}$ of weight in average) than those from control group (Fig. 6d-6f). Representative images of the implantation sites in mouse uteruses and embryos obtained from different conditions are shown in Fig. $6 \mathrm{~b}$ and $6 \mathrm{~d}$. These analyses revealed that intra-uterine CXCL12 treatment elevates the rates of embryo implantation and maintains the pregnancy with no regression of embryos. Even though further analyses on karyotyping examination on embryos obtained from each group will be essentially required for the safety issues prior to the clinical application, non-invasive CXCL12 intra-uterine treatment might be suggested as an effective therapeutic strategy for the infertility patients who are suffering from repeated failure of implantation with insufficient endometrial receptivity.

\section{Discussion}

Successful implantation is a complex sequential signaling process mediated by bi-directional crosstalk between the embryo and endometrium, which is enabled by the synchronous development of the embryo and receptive endometrium especially during the early phase of embryo implantation $[53,54]$. Our present study identified that embryo-derived chemokine CXCL12 interacts with endometrial CXCR4 and CXCR7 enhancing endometrial receptivity and angiogenesis. This has been fully demonstrated in vivo by showing that the intrauterine administration of recombinant CXCL12 induces cellular and molecular features of improved endometrial receptivity exhibiting remarkably elevated integrin $\beta 3, L I F$, and glycodelin, and promoted endometrial angiogenesis displaying increased numbers of newly formed vessels accompanied by higher CD31 and CD34. Moreover, significantly enhanced rates of embryo implantation were observed in CXCL12-treated mouse uterine horns. Even though the detailed molecular mechanisms underlying CXCL12-induced endometrial angiogenesis and its direct or indirect correlation with improved implantation rates remain to be defined, this might suggest intrauterine application of CXCL12, which is completely non-invasive causing no traumatic injury to the endometrium at all, as an effective therapeutic strategy for patients suffering from repeated implantation failure caused by insufficient endometrial receptivity.

During the process of embryo implantation, the embryo enters the uterine cavity and adheres to the endometrial luminal epithelium inducing the local molecular and cellular alterations in the endometrium. It has been previously reported that the number of genes, including SNAI2, TGF-B1, SPARC, and Jagged1, were nominated by showing the alterations in human endometrial epithelial cells with the treatment of conditioned medium derived from human blastocysts culture following in vitro fertilization [55]. Additionally, significantly increased endometrial HOXA10 expression by blastocyst-secreted factors was observed [56,57]. Increased expression of endometrial luteinizing hormone/choriogonadotropin receptor 
(LHCGR) is a direct response to embryo-secreted chorionic gonadotropin and this interaction results in the expression of cyclooxygenase-2 and prostaglandin E synthase through the activation of extracellular signal-regulated protein kinase 1/2 (ERK1/2) signaling pathway $[58,59]$. These evidences strongly imply that embryo-derived secreted factors act as main modulators of regulating the local status of endometrial receptivity during the embryo implantation or prior to implantation. A number of chemokines, including CXCL12 and its ligand CXCR4, have been reported to be expressed at the embryo-maternal interface during implantation and placentation [60]. To support these previous findings, in our current study CXCL12 has been validated as an embryo-secreted factor by detecting from the embryo culture medium and its ligand CXCR4 and CXCR7 are localized to the endometrial epithelial cells and their expressions are increased with CXCL12 treatment (Fig. 1). Dysregulation of CXCL12/CXCR4/CXCR7 axis leads to placental dysfunction by attenuating trophoblast invasion and migration, and contributes to pregnancy disorders including preeclampsia, miscarriage, and fetal growth restriction [61, 62]. Although CXCL12 was detected in human first-trimester villous cytotrophoblasts, syncytiotrophoblasts, and extravillous cytotrophoblast cells, and its ligand CXCR4 expression in decidual stromal cells suggesting a crucial role of CXCL12-CXCR4 axis in the crosstalk between trophoblast cells and endometrial stromal cells during the process of embryo implantation and early pregnancy [63], its direct clinical impact as a therapeutic intervention to improve the endometrial receptivity and pregnancy rate has not been proved yet.

Our present study showed that intra-uterine administration of CXCL12 increased endometrial receptivity and promoted endometrial angiogenesis, and it dramatically enhanced the pregnancy rates. Molecular mechanisms underlying these potential consequences might be supported by the fact that the CXCL12CXCR4 interaction is known to promote cell-cell adhesion between the embryo and endometrium by induction of endometrial integrin family, notably alpha3, alpha5, beta1, and beta3 subunits, accompanied by increased phosphorylation of ERK1/2, JNK, and p38 pathway. This results in enhancement of cell-cell adhesion between the embryo and endometrium, trophoblast invasion, and endothelial angiogenesis [64, 65]. Recently, it has been reported that invasive CXCL12 injection to the uterine muscle layer demonstrated a beneficial effect for endometrial regeneration on the improvement of endometrial receptivity of thin endometrium with the combined treatment with bone marrow-derived mesenchymal stem cells [66]. CXCL12 was suggested as a potent chemoattractant of bone marrow-derived mesenchymal stem cells mediating immunomodulatory actions and promoting angiogenesis [67]. Moreover, as an effective chemotactic factor for T cell, CXCL12 has been demonstrated to modulate the regulatory $\mathrm{T}$ cells to migrate into the pregnant uterus by binding its ligand CXCR4 and establish a beneficial microenvironment for the fetus [68]. To support these previous reports, our data showed that angiogenesis-related gene expression was significantly increased by CXCL12 and higher numbers of newly formed blood vessels were observed in CXCL12-administered mouse uterus. Consistent with previous report, CXCL12 enhanced the formation and maturation of blood vessels within the co-culture system of endometrial stromal cells with endothelial cells (Fig. 4). Of note, in our current study we applied CXCL12 into the uterine cavity with a non-invasive method, which is completely distinguishable to other studies, rendering dramatic impacts on improvement of pregnancy rates particularly during the embryo implantation without any retarded embryos. 


\section{Conclusions}

In summary, our present study provides a novel evidence suggesting CXCL12 treatment as an efficient therapeutic intervention to improve the endometrial microenvironment by increasing endometrial receptivity and angiogenesis. Further study will be required to discover the molecular and cellular regulation of CXCL12 to the induction of endometrial receptivity and angiogenesis, and evaluate the reproductive toxicity of intra-uterine application of CXCL12 prior to clinical trials. A better understanding of uterine endometrial receptivity and angiogenesis induced by embryo-derived chemokine CXCL12 may aid to develop a non-invasive therapeutic strategy for clinical treatment or supplement for the patients with repeated implantation failure with less risk.

\section{Declarations}

\section{Declarations}

\section{Consent for publication}

The content of the manuscript has been approved by all the authors.

\section{Ethics approval and consent to participate}

Not applicable

\section{Availability of data and materials}

RNA-seq data that support the findings of this study have been deposited in GEO with the primary accession code GSE154039. The authors declare that all other data supporting the findings of this study are available within the article and its Supplementary information files. Please contact the corresponding author for data on reasonable request.

\section{Competing interests}

The authors declare that there are no competing interests.

\section{Funding}

This work is supported by funding from a National Research Foundation of Korea (NRF) grant funded by the Korean government (No. 2018R1C1B6003) to Y.-J.K, and a National Research Foundation of Korea (NRF) grant funded by the Korea government (MSIP; Ministry of Science, ICT \& Future Planning) (No. 2018M3A9E806624623) to H.S.K.

\section{Author's contributions}


YJK and HSK planned the studies, conducted analysis and interpretation of all experiments; MJY, SHH, and JA conducted experiments; and HC, DL, HK, DHC, KAL, and JJK contributed to critical discussion; and HSK and YJK wrote the manuscript.

\section{Acknowledgements}

This study was supported by a National Research Foundation of Korea (NRF) grant funded by the Korean government (No. 2018R1C1B6003 and 2018M3A9E806624623).

\section{Author details}

${ }^{1}$ CHA Fertility Center Bundang, CHA University, Seongnam-si, Gyunggi-do, South Korea. ${ }^{2}$ Department of Biomedical Science, School of Life Science, CHA University, Seongnam-si, Gyunggi-do, South Korea.

${ }^{3}$ Department of Biochemistry, School of Medicine, CHA University, Seongnam-si, Gyunggi-do, South Korea

\section{References}

1. Aplin JD, Ruane PT. Embryo-epithelium interactions during implantation at a glance. J Cell Sci. 2017;130(1):15-22.

2. Dey SK, Lim H, Das SK, Reese J, Paria BC, Daikoku T, Wang H. Molecular cues to implantation. Endocr Rev. 2004;25(3):341-73.

3. Psychoyos A. Hormonal control of ovoimplantation. Vitam Horm. 1973;31:201-56.

4. Diedrich K, Fauser BC, Devroey P, Griesinger G, Evian Annual Reproduction Workshop G. The role of the endometrium and embryo in human implantation. Hum Reprod Update. 2007;13(4):365-77.

5. de Mouzon J, Goossens V, Bhattacharya S, Castilla JA, Ferraretti AP, Korsak V, Kupka M, Nygren KG, Nyboe Andersen A, European Ivf-monitoring Consortium ftESoHR et al: Assisted reproductive technology in Europe, 2006: results generated from European registers by ESHRE. Hum Reprod 2010, 25(8):1851-1862.

6. Ferraretti AP, Goossens V, Kupka M, Bhattacharya S, de Mouzon J, Castilla JA, Erb K, Korsak V, Nyboe Andersen A, European IVFMCftESoHR. et al: Assisted reproductive technology in Europe, 2009: results generated from European registers by ESHRE. Hum Reprod. 2013;28(9):2318-31.

7. Paulson RJ. Hormonal induction of endometrial receptivity. Fertil Steril. 2011;96(3):530-5.

8. Strowitzki T, Germeyer A, Popovici R, von Wolff M. The human endometrium as a fertility-determining factor. Hum Reprod Update. 2006;12(5):617-30.

9. Zhou WH, Wu X, Hu WD, Du MR. Co-expression of CXCR4 and CXCR7 in human endometrial stromal cells is modulated by steroid hormones. Int J Clin Exp Pathol. 2015;8(3):2449-60.

10. Margalioth EJ, Ben-Chetrit A, Gal M, Eldar-Geva T. Investigation and treatment of repeated implantation failure following IVF-ET. Hum Reprod. 2006;21(12):3036-43.

11. Bashiri A, Halper KI, Orvieto R. Recurrent Implantation Failure-update overview on etiology, diagnosis, treatment and future directions. Reprod Biol Endocrinol. 2018;16(1):121. 
12. Koot YE, Teklenburg G, Salker MS, Brosens JJ, Macklon NS. Molecular aspects of implantation failure. Biochim Biophys Acta. 2012;1822(12):1943-50.

13. Mahajan N. Endometrial receptivity array: Clinical application. J Hum Reprod Sci. 2015;8(3):121-9.

14. Zhou Q, Yan G, Ding L, Liu J, Yu X, Kong S, Zhang M, Wang Z, Liu Y, Jiang Y, et al. EHD1 impairs decidualization by regulating the Wnt4/beta-catenin signaling pathway in recurrent implantation failure. EBioMedicine. 2019;50:343-54.

15. Bielfeld AP, Pour SJ, Poschmann G, Stuhler K, Krussel JS, Baston-Bust DM. A Proteome Approach Reveals Differences between Fertile Women and Patients with Repeated Implantation Failure on Endometrial Level(-)Does hCG Render the Endometrium of RIF Patients? Int J Mol Sci 2019, 20(2).

16. Gambino LS, Wreford NG, Bertram JF, Dockery P, Lederman F, Rogers PA. Angiogenesis occurs by vessel elongation in proliferative phase human endometrium. Hum Reprod. 2002;17(5):1199-206.

17. Rogers PA. Structure and function of endometrial blood vessels. Hum Reprod Update. 1996;2(1):5762.

18. Rogers PA, Donoghue JF, Walter LM, Girling JE. Endometrial angiogenesis, vascular maturation, and lymphangiogenesis. Reprod Sci. 2009;16(2):147-51.

19. Torry DS, Leavenworth J, Chang M, Maheshwari V, Groesch K, Ball ER, Torry RJ. Angiogenesis in implantation. J Assist Reprod Genet. 2007;24(7):303-15.

20. Kim A, Jung H, Choi WJ, Hong SN, Kim HY. Detection of endometrial and subendometrial vasculature on the day of embryo transfer and prediction of pregnancy during fresh in vitro fertilization cycles. Taiwan J Obstet Gynecol. 2014;53(3):360-5.

21. Merce LT, Barco MJ, Bau S, Troyano J. Are endometrial parameters by three-dimensional ultrasound and power Doppler angiography related to in vitro fertilization/embryo transfer outcome? Fertil Steril. 2008;89(1):111-7.

22. Kim H, Shin JE, Koo HS, Kwon H, Choi DH, Kim JH. Effect of Autologous Platelet-Rich Plasma Treatment on Refractory Thin Endometrium During the Frozen Embryo Transfer Cycle: A Pilot Study. Front Endocrinol (Lausanne). 2019;10:61.

23. Xie Y, Zhang T, Tian Z, Zhang J, Wang W, Zhang H, Zeng Y, Ou J, Yang Y. Efficacy of intrauterine perfusion of granulocyte colony-stimulating factor (G-CSF) for Infertile women with thin endometrium: A systematic review and meta-analysis. Am J Reprod Immunol 2017, 78(2).

24. Zhu X, Peault B, Yan G, Sun H, Hu Y, Ding L. Stem Cells and Endometrial Regeneration: From Basic Research to Clinical Trial. Curr Stem Cell Res Ther. 2019;14(4):293-304.

25. Du J, Lu H, Yu X, Lu Z, Mi L, Zhang X. Efficacy and safety of platelet-rich plasma for the treatment of thin endometrium: A protocol for systematic review and meta-analysis. Medicine. 2020;99(3):e18848.

26. Yin M, Zhou HJ, Lin C, Long L, Yang X, Zhang H, Taylor H, Min W. CD34(+)KLF4(+) Stromal Stem Cells Contribute to Endometrial Regeneration and Repair. Cell Rep. 2019;27(9):2709-24 e2703. 
27. Zhao J, Xu B, Xie S, Zhang Q, Li YP. Whether G-CSF administration has beneficial effect on the outcome after assisted reproductive technology? A systematic review and meta-analysis. Reprod Biol Endocrinol. 2016;14(1):62.

28. Dominguez F, Pellicer A, Simon C. The chemokine connection: hormonal and embryonic regulation at the human maternal-embryonic interface-a review. Placenta. 2003;24(Suppl B):48-55.

29. Hanna J, Wald O, Goldman-Wohl D, Prus D, Markel G, Gazit R, Katz G, Haimov-Kochman R, Fujii N, Yagel S, et al. CXCL12 expression by invasive trophoblasts induces the specific migration of CD16human natural killer cells. Blood. 2003;102(5):1569-77.

30. Zuccarello D, Ferlin A, Garolla A, Menegazzo M, Perilli L, Ambrosini G, Foresta C. How the human spermatozoa sense the oocyte: a new role of SDF1-CXCR4 signalling. Int J Androl. 2011;34(6 Pt 2):e554-65.

31. Zheng J, Wang H, Zhou W. Modulatory effects of trophoblast-secreted CXCL12 on the migration and invasion of human first-trimester decidual epithelial cells are mediated by CXCR4 rather than CXCR7. Reprod Biol Endocrinol. 2018;16(1):17.

32. Kang YJ, Lees M, Matthews LC, Kimber SJ, Forbes K, Aplin JD. MiR-145 suppresses embryo-epithelial juxtacrine communication at implantation by modulating maternal IGF1R. J Cell Sci. 2015;128(4):804-14.

33. Kang YJ, Forbes K, Carver J, Aplin JD. The role of the osteopontin-integrin alphavbeta3 interaction at implantation: functional analysis using three different in vitro models. Hum Reprod. 2014;29(4):73949.

34. Chung M, Ahn J, Son K, Kim S, Jeon NL. Biomimetic Model of Tumor Microenvironment on Microfluidic Platform. Adv Healthc Mater 2017, 6(15).

35. Kang YJ, Balter B, Csizmadia E, Haas B, Sharma H, Bronson R, Yan CT. Contribution of classical endjoining to PTEN inactivation in p53-mediated glioblastoma formation and drug-resistant survival. Nat Commun. 2017;8:14013.

36. Fujita M, Davari P, Takada YK, Takada Y. Stromal cell-derived factor-1 (CXCL12) activates integrins by direct binding to an allosteric ligand-binding site (site 2) of integrins without CXCR4. Biochem J. 2018;475(4):723-32.

37. Martin SK, Diamond P, Williams SA, To LB, Peet DJ, Fujii N, Gronthos S, Harris AL, Zannettino AC. Hypoxia-inducible factor- 2 is a novel regulator of aberrant CXCL12 expression in multiple myeloma plasma cells. Haematologica. 2010;95(5):776-84.

38. Herbert SP, Stainier DY. Molecular control of endothelial cell behaviour during blood vessel morphogenesis. Nat Rev Mol Cell Biol. 2011;12(9):551-64.

39. Zhang M, Qiu L, Zhang Y, Xu D, Zheng JC, Jiang L. CXCL12 enhances angiogenesis through CXCR7 activation in human umbilical vein endothelial cells. Sci Rep. 2017;7(1):8289.

40. Zheng J, Qu D, Wang C, Ding L, Zhou W. Involvement of CXCL12/CXCR4 in the motility of human first-trimester endometrial epithelial cells through an autocrine mechanism by activating PI3K/AKT signaling. BMC Pregnancy Childbirth. 2020;20(1):87. 
41. Pavlidis I, Spiller OB, Sammut Demarco G, MacPherson H, Howie SEM, Norman JE, Stock SJ. Cervical epithelial damage promotes Ureaplasma parvum ascending infection, intrauterine inflammation and preterm birth induction in mice. Nat Commun. 2020;11(1):199.

42. Huang da W, Sherman BT, Lempicki RA. Systematic and integrative analysis of large gene lists using DAVID bioinformatics resources. Nat Protoc. 2009;4(1):44-57.

43. Shin M, Beane TJ, Quillien A, Male I, Zhu LJ, Lawson ND. Vegfa signals through ERK to promote angiogenesis, but not artery differentiation. Development. 2016;143(20):3796-805.

44. Zhang EY, Gao B, Shi HL, Huang LF, Yang L, Wu XJ, Wang ZT. 20(S)-Protopanaxadiol enhances angiogenesis via HIF-1alpha-mediated VEGF secretion by activating p70S6 kinase and benefits wound healing in genetically diabetic mice. Exp Mol Med. 2017;49(10):e387.

45. Ruan YC, Chen $\mathrm{H}$, Chan HC. Ion channels in the endometrium: regulation of endometrial receptivity and embryo implantation. Hum Reprod Update. 2014;20(4):517-29.

46. Achache H, Revel A. Endometrial receptivity markers, the journey to successful embryo implantation. Hum Reprod Update. 2006;12(6):731-46.

47. Kelleher AM, Milano-Foster J, Behura SK, Spencer TE. Uterine glands coordinate on-time embryo implantation and impact endometrial decidualization for pregnancy success. Nat Commun. 2018;9(1):2435.

48. Kelleher AM, Burns GW, Behura S, Wu G, Spencer TE. Uterine glands impact uterine receptivity, luminal fluid homeostasis and blastocyst implantation. Sci Rep. 2016;6:38078.

49. Cooke PS, Spencer TE, Bartol FF, Hayashi K. Uterine glands: development, function and experimental model systems. Mol Hum Reprod. 2013;19(9):547-58.

50. Guo F, Si C, Zhou M, Wang J, Zhang D, Leung PCK, Xu B, Zhang A. Decreased PECAM1-mediated TGF-beta1 expression in the mid-secretory endometrium in women with recurrent implantation failure. Hum Reprod. 2018;33(5):832-43.

51. Zhou X, Xu B, Zhang D, Jiang X, Chang HM, Leung PCK, Xia X, Zhang A. Loss of CDYL Results in Suppression of CTNNB1 and Decreased Endometrial Receptivity. Front Cell Dev Biol. 2020;8:105.

52. Mints $M$, Jansson $M$, Sadeghi B, Westgren M, Uzunel M, Hassan M, Palmblad J. Endometrial endothelial cells are derived from donor stem cells in a bone marrow transplant recipient. Hum Reprod. 2008;23(1):139-43.

53. Simon C, Martin JC, Pellicer A. Paracrine regulators of implantation. Baillieres Best Pract Res Clin Obstet Gynaecol. 2000;14(5):815-26.

54. Simon C, Martin JC, Meseguer M, Caballero-Campo P, Valbuena D, Pellicer A. Embryonic regulation of endometrial molecules in human implantation. J Reprod Fertil Suppl. 2000;55:43-53.

55. Cuman C, Menkhorst EM, Rombauts LJ, Holden S, Webster D, Bilandzic M, Osianlis T, Dimitriadis E. Preimplantation human blastocysts release factors that differentially alter human endometrial epithelial cell adhesion and gene expression relative to IVF success. Hum Reprod. 2013;28(5):116171. 
56. Sakkas D, Lu C, Zulfikaroglu E, Neuber E, Taylor HS. A soluble molecule secreted by human blastocysts modulates regulation of HOXA10 expression in an epithelial endometrial cell line. Fertil Steril. 2003;80(5):1169-74.

57. Yamagami K, Islam MR, Yoshii Y, Mori K, Tashiro K, Yamauchi N. Preimplantation embryo-secreted factors modulate maternal gene expression in rat uterus. Cell Tissue Res. 2016;364(2):453-63.

58. Banerjee P, Sapru K, Strakova Z, Fazleabas AT. Chorionic gonadotropin regulates prostaglandin E synthase via a phosphatidylinositol 3-kinase-extracellular regulatory kinase pathway in a human endometrial epithelial cell line: implications for endometrial responses for embryo implantation. Endocrinology. 2009;150(9):4326-37.

59. Srisuparp S, Strakova Z, Brudney A, Mukherjee S, Reierstad S, Hunzicker-Dunn M, Fazleabas AT. Signal transduction pathways activated by chorionic gonadotropin in the primate endometrial epithelial cells. Biol Reprod. 2003;68(2):457-64.

60. Dimitriadis E, White CA, Jones RL, Salamonsen LA. Cytokines, chemokines and growth factors in endometrium related to implantation. Hum Reprod Update. 2005;11(6):613-30.

61. Warner JA, Zwezdaryk KJ, Day B, Sullivan DE, Pridjian G, Morris CA. Human cytomegalovirus infection inhibits CXCL12- mediated migration and invasion of human extravillous cytotrophoblasts. Virol J. 2012;9:255.

62. Wang L, Li X, Zhao Y, Fang C, Lian Y, Gou W, Han T, Zhu X. Insights into the mechanism of CXCL12mediated signaling in trophoblast functions and placental angiogenesis. Acta Biochim Biophys Sin (Shanghai). 2015;47(9):663-72.

63. Ren L, Liu YQ, Zhou WH, Zhang YZ. Trophoblast-derived chemokine CXCL12 promotes CXCR4 expression and invasion of human first-trimester decidual stromal cells. Hum Reprod. 2012;27(2):366-74.

64. Engl T, Relja B, Marian D, Blumenberg C, Muller I, Beecken WD, Jones J, Ringel EM, Bereiter-Hahn J, Jonas $\mathrm{D}$, et al. CXCR4 chemokine receptor mediates prostate tumor cell adhesion through alpha5 and beta3 integrins. Neoplasia. 2006;8(4):290-301.

65. Sun H, Liu J, Zheng Y, Pan Y, Zhang K, Chen J. Distinct chemokine signaling regulates integrin ligand specificity to dictate tissue-specific lymphocyte homing. Dev Cell. 2014;30(1):61-70.

66. Yi KW, Mamillapalli R, Sahin C, Song J, Tal R, Taylor HS. Bone marrow-derived cells or C-X-C motif chemokine 12 (CXCL12) treatment improve thin endometrium in a mouse model. Biol Reprod. 2019;100(1):61-70.

67. Sahin Ersoy G, Zolbin MM, Cosar E, Moridi I, Mamillapalli R, Taylor HS. CXCL12 Promotes Stem Cell Recruitment and Uterine Repair after Injury in Asherman's Syndrome. Mol Ther Methods Clin Dev. 2017;4:169-77.

68. Lin Y, Xu L, Jin H, Zhong Y, Di J, Lin QD. CXCL12 enhances exogenous CD4 + CD25 + T cell migration and prevents embryo loss in non-obese diabetic mice. Fertil Steril. 2009;91(6):2687-96.

\section{Figures}


a

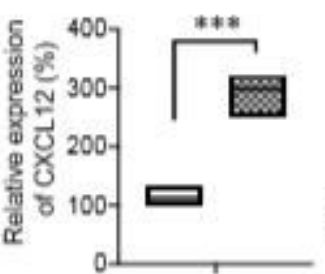

b

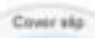

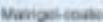

प्याओयद्व

C

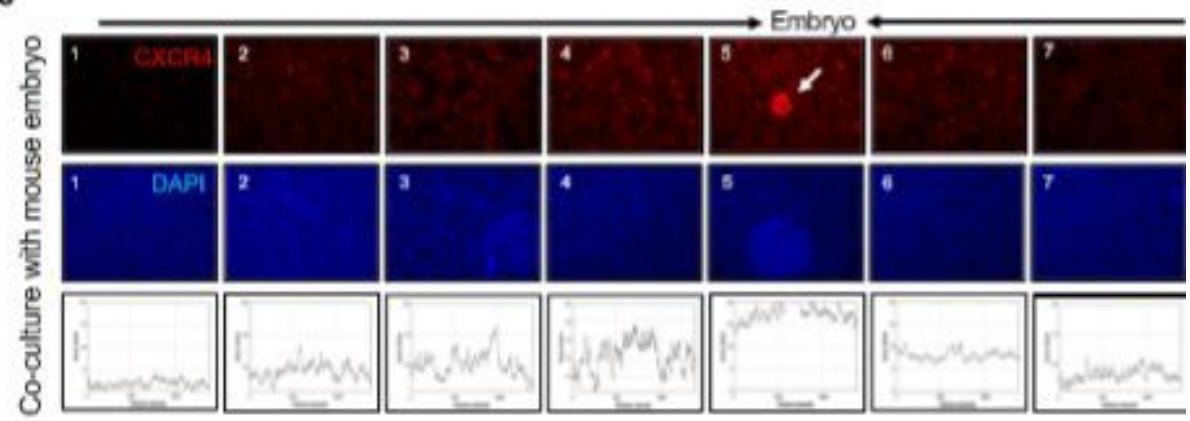

d

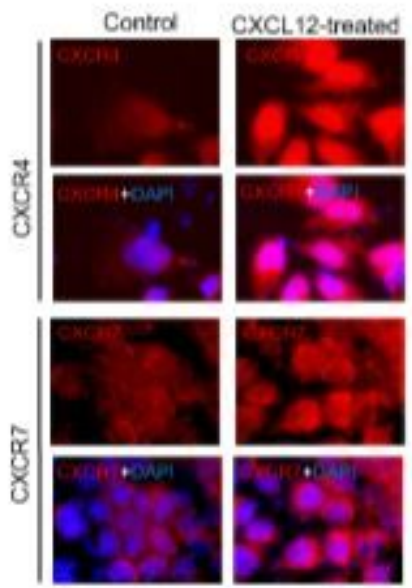

e

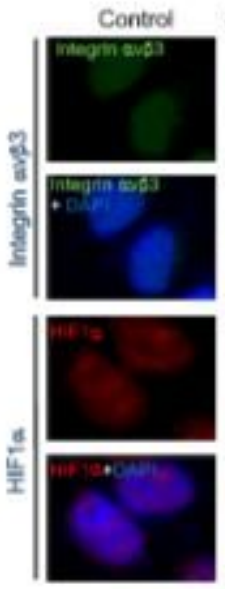

CXCL12-treated
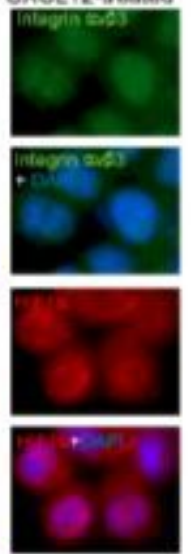

Figure 1

Embryo-derived chemokine CXCL12 and its ligand endometrial CXCR4/CXCR7 (a) CXCL12 levels were quantified in embryo culture or empty medium by ELISA. (b) A schematic diagram of co-culture system of mouse embryo with Ishikawa cells on Matrigel-coated coverslip. (c) Immunofluorescence (IF) staining images (1-7) were obtained from 7 different regions (illustrated on a diagram of (b:1-7)) of coverslip and mouse embryo (white arrow) was attached in the region number 5 (illustrated on a diagram of (b), marked as red spot). Red: CXCR4, Blue: DAPI. Intensity of CXCR4 in each image was profiled. Images were captured at a magnification of $10 x$. IF staining of CXCR4, CXCR7 (d) and integrin $₫ \vee \beta 3, H I F 1 \rrbracket(e)$ in Ishikawa cells in response to CXCL12. Saline-treated cells were used for control. 
a

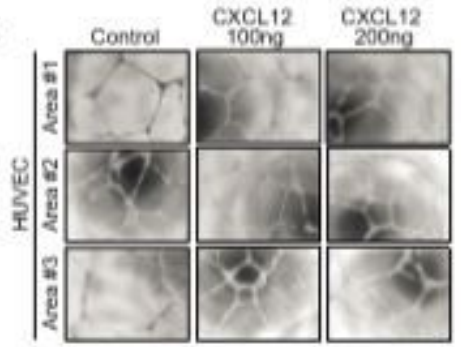

b

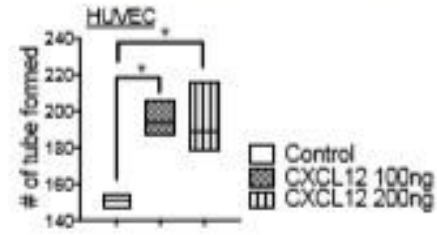

c

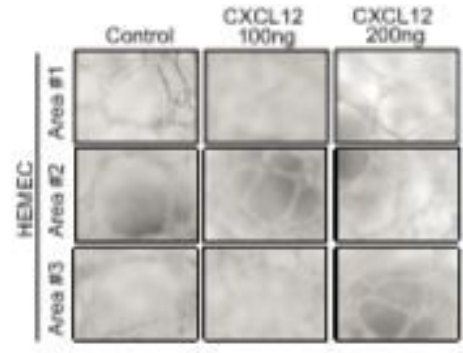

d

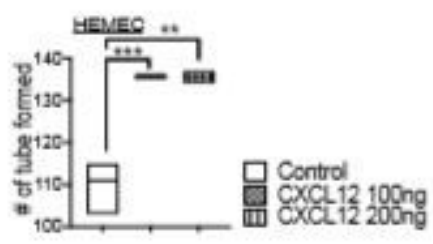

e

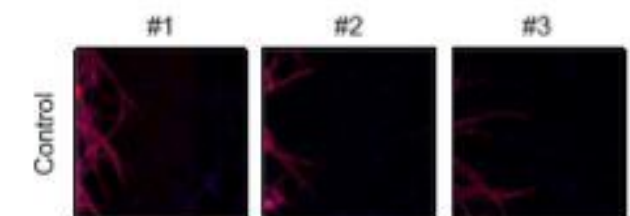

f
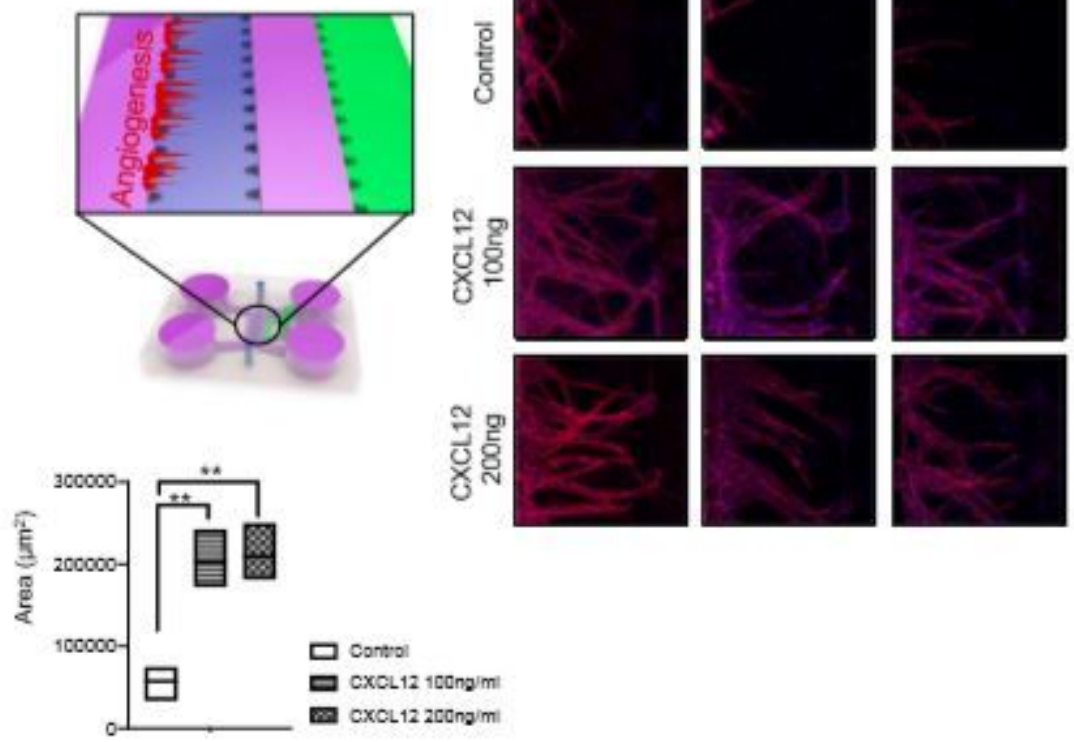

Figure 2

The role of CXCL12 treatment in vessel formation of vascular endothelial cells Representative images showing tube formation of HUVEC (a-b) or HEMEC (c-d) in the absence or presence of CXCL12 $(100 \mathrm{ng} / \mathrm{ml}$ or $200 \mathrm{ng} / \mathrm{ml}$ ) for $48 \mathrm{~h}$. The total number of tube loops was quantified in graphs shown in (b) and (d). (e) A micro-engineered vascular system to detect the angiogenic effect of CXCL12. Representative confocal microscopic images of angiogenic sprouting of HUVECs in response to CXCL12. The total surface area of HUVEC sprouting was quantified in a graph shown in (f). Data shown in (f) are from 3 independent experiments and analyzed using the ordinary one-way ANOVA analysis with Dunnett's multiple comparison test including P-values ( $*<0.05, * \star<0.01, * \star \star<0.001, * \star \star \star<0.0001$, NS; not significant). 
a
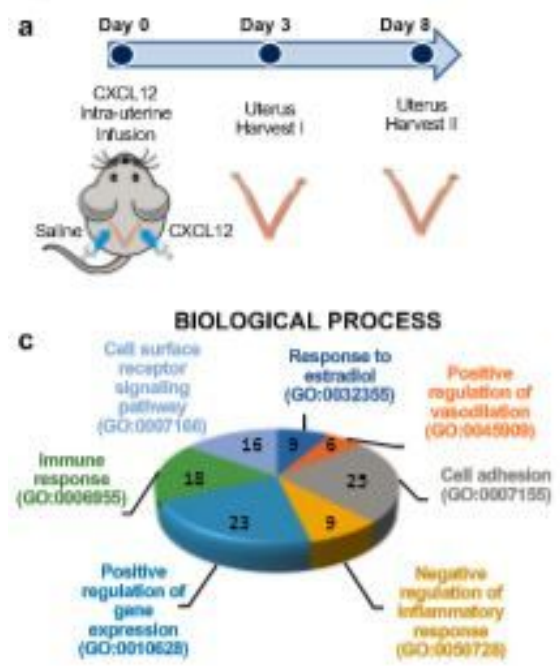

d

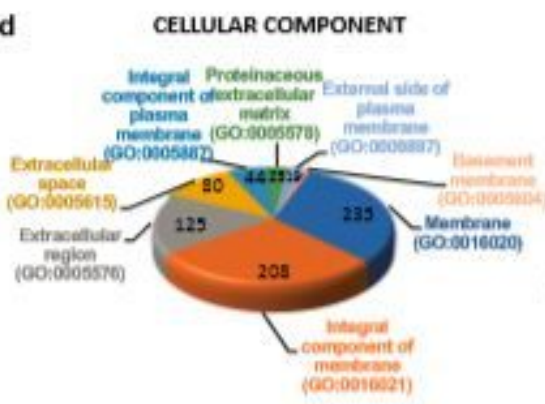

e

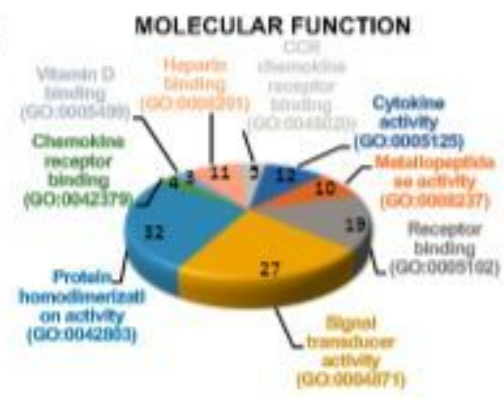

b
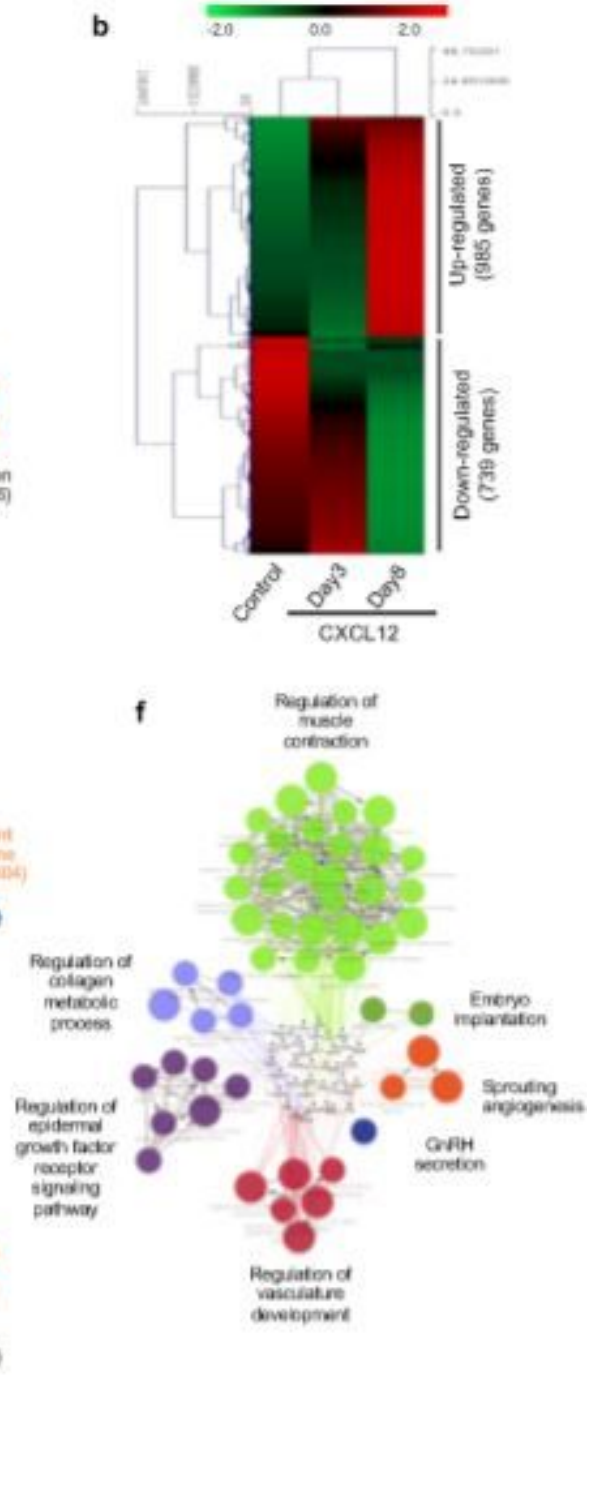

Figure 3

Identification of differentially expressed genes between the CXCL12-treated uterus vs. control (a) A schematic diagram of experimental plan of intrauterine CXCL12 administration. (b) Unsupervised hierarchical clustering analysis of RNA seq visualizing a heatmap plot showing differentially expressed genes (DEGs) in CXCL12-treated group vs control. Each row represents a distinct sample (6 independent CXCL12-treated groups compared to saline-treated control) and each column represents an individual gene (a list of 23282 genes). Normalized (log2) and standardized (each sample to mean signal=0 and standard deviation=1) level of gene expression is denoted by color (green; low, dark; intermediate, red; high), as indicated in the gradient panel. (c-e) Pie charts displaying gene ontology (GO) and pathway analysis of differentially expressed genes between CXCL12-treated (Day 8) and control using DAVID tool and gene count numbers on each pie chart. The cutoff for significance was set by $P<0.05$. (c) Biological Process (BP), (d) Cellular Component (CC), and (e) Molecular Function (MF). (f) A network of gene-gene interaction among CXCL12-regulated genes was constructed displaying specifically enriched signaling pathways. 
a
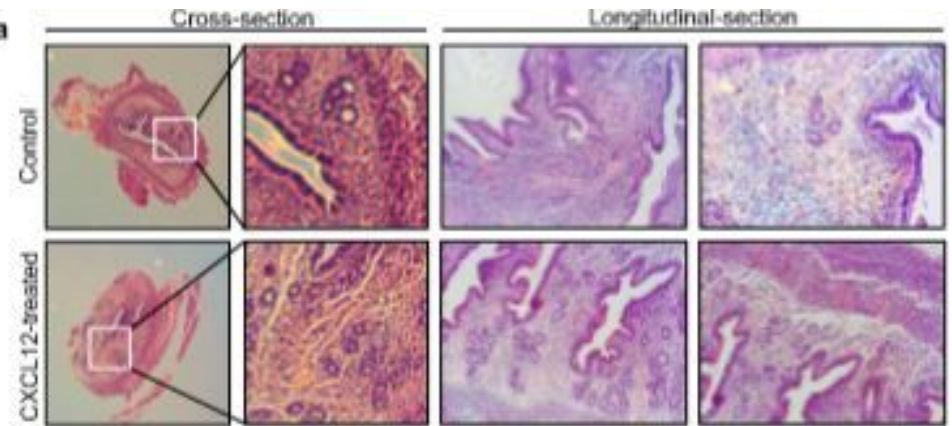

b
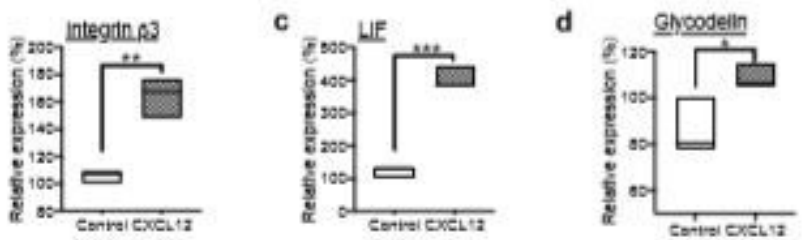

e
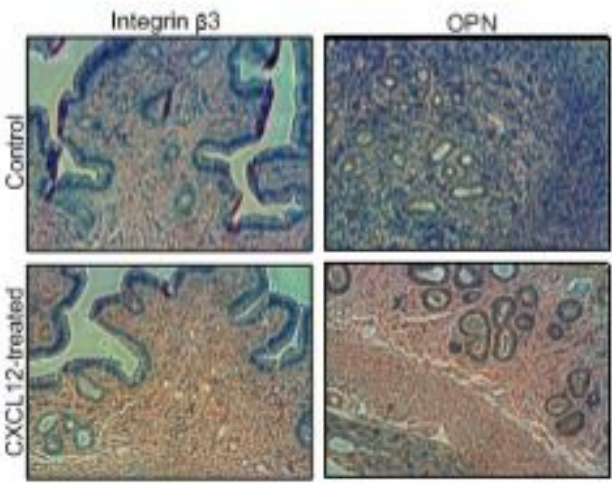

Figure 4

Increased endometrial receptivity with intra-uterine CXCL12 treatment (a) H\&E staining of cross-sectioned or longitudinally-sectioned mouse uterus harvested 8 days after CXCL12 treatment. (b-d) QRT-PCR analysis of integrin $\beta 3, L I F$, and Glycodelin in CXCL12-treated uterus samples compared to controls. (e) Immunohistochemical staining of integrin $\beta 3$ and OPN in CXCL12-treated uterus samples compared to controls. 

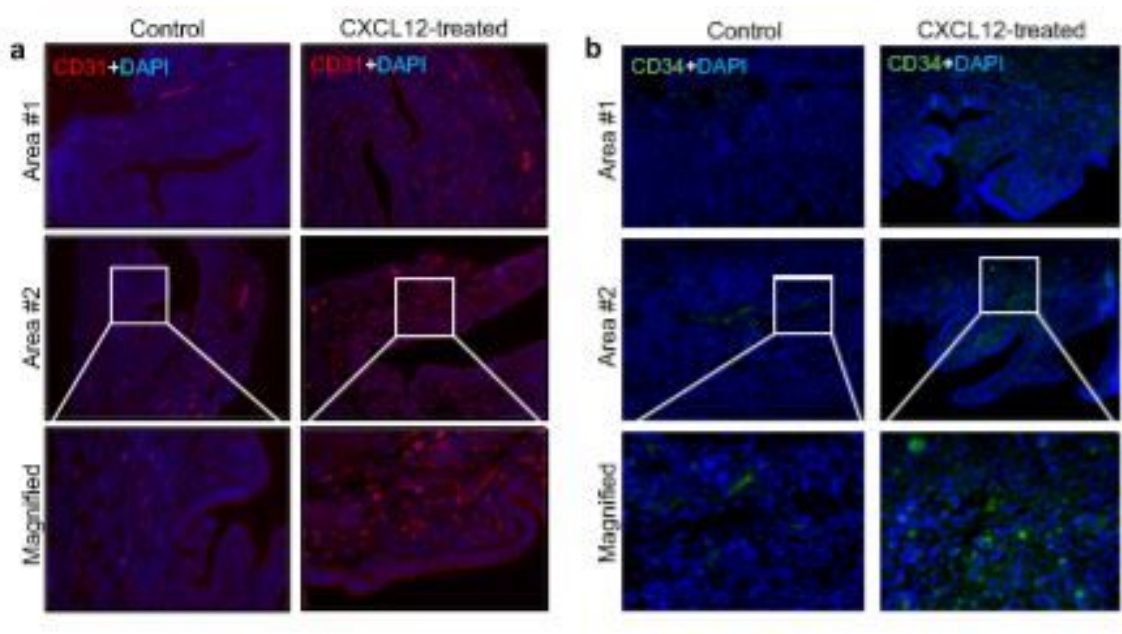

c

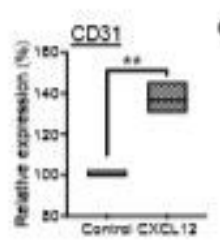

d
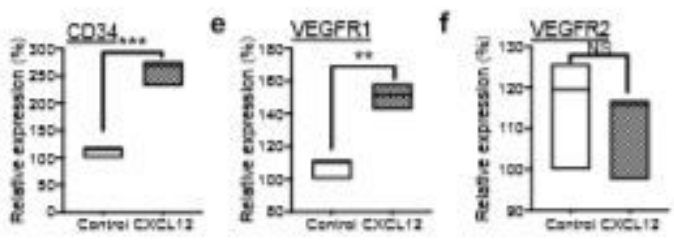

g
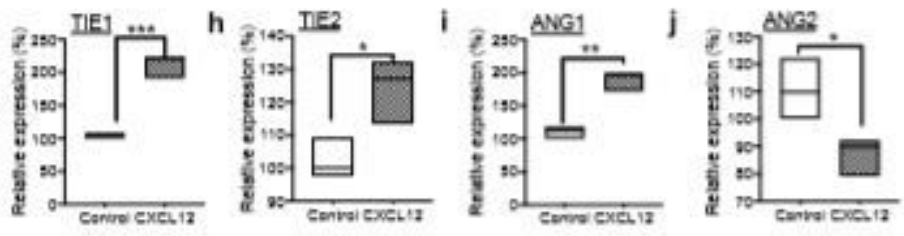

\section{Figure 5}

Promoted endometrial angiogenesis with intra-uterine CXCL12 treatment IF staining of CD31 (a) or CD34 (b) in longitudinally sectioned mouse uterus harvested 8 days after CXCL12 intrauterine infusion. Salinetreated endometrium were used for control. (c-j) QRT-PCR analysis of CD31, CD34, VEGFR1, VEGFR2, TIE1, TIE2, ANG1 and ANG2 in CXCL12-treated uterus samples compared to controls. 


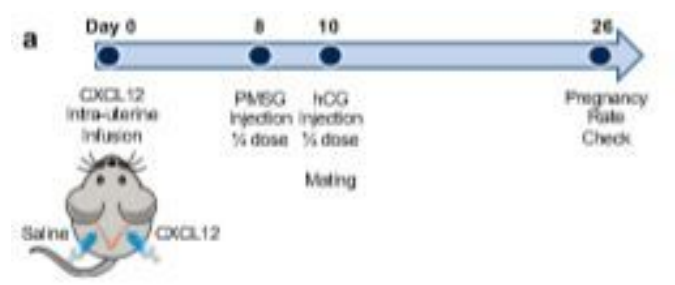

b
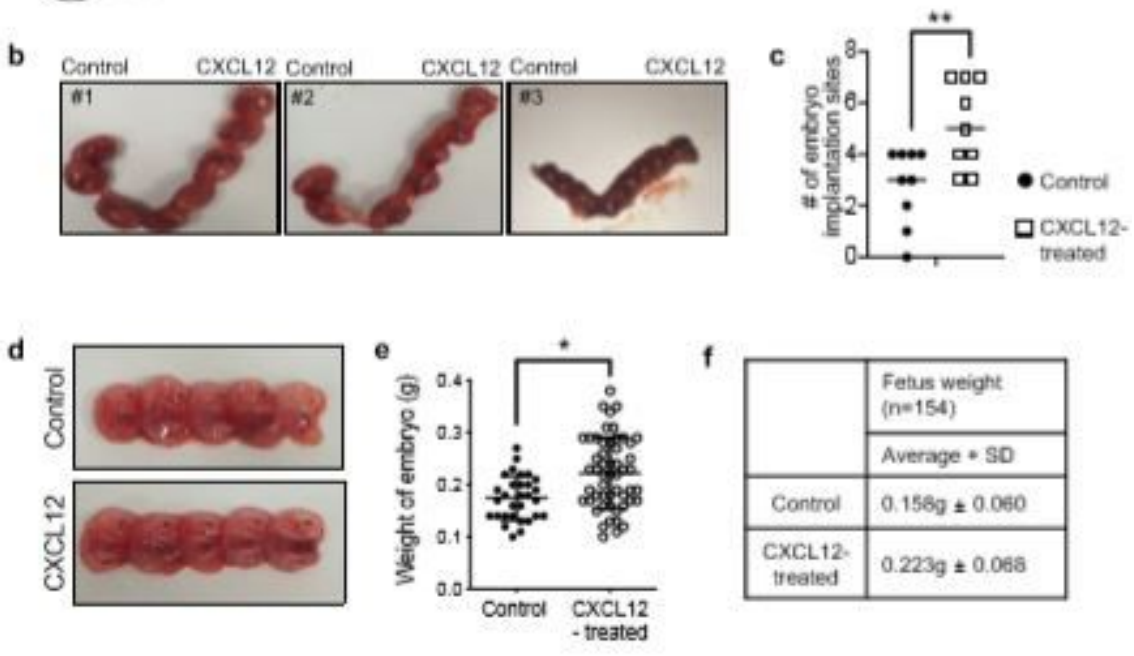

Figure 6

Impact of non-invasive intra-uterine CXCL12 treatment on the pregnancy rates (a) A schematic diagram of an experimental plan for the fertility assessment followed by intra-uterine CXCL12 infusion. (b) Representative images of CXCL12-treated uteruses including sites of embryo implantation compared to saline-treated controls. Average numbers of embryo implantation sites were quantified in the graph shown in (c). (d) Representative images of embryos obtained from CXCL12-treated or saline-treated mouse uterus. (e-f) Average weight of embryos obtained from CXCL12-treated uterus compared to control. Data shown for (b-f) are from 3 independent experiments (\# of mice; 34, \# of embryos; 162), and analyzed using the ordinary one-way ANOVA analysis with Dunnett's multiple comparison test including P-values ( ${ }^{*}<0.05$, NS; not significant).

\section{Supplementary Files}

This is a list of supplementary files associated with this preprint. Click to download.

- CellandBioscienceSupplementaryTable1KYJ.docx

- CellandBioscienceCXCL12SuppleFigureKYJ.pdf 